\title{
Does Spousal Support Moderate the Association Between Perceived Racial Discrimination and Depressive Symptoms among African American Couples?
}

\author{
SHARDE' N. MCNEIL* \\ FRANK D. FINCHAM* \\ STEVEN R. H. BEACH
}

Social stress theory proposes that stress resulting from one's social position in society leads to fewer coping resources, and subsequently causes an increase in mental health problems. Guided by this framework, we investigated whether the relationship between perceived discrimination and depressive symptoms was moderated by spousal social support in a sample of 487 African American heterosexual couples. Using the actor-partner interdependence model, findings suggested that female partner's perceived racial discrimination was predictive of her depressive symptomology irrespective of spousal support and male partner's perceived racial discrimination was predictive of depressive symptomology only among men with low levels of spousal support. No partner effects were present. The results demonstrate the need to examine variability in social stress and mental health outcomes for those in close relationships.

Keywords: Stressors; African American; Couples; Depression; Discrimination; Spousal Support

Fam Proc $x: 1-11,2013$

$\mathrm{M}$ ental health outcomes among African Americans have been associated with experiencing high amounts of stress resulting directly and indirectly from racial discrimination (Lincoln \& Chae, 2010; Ong, Fuller-Rowell, \& Burrow, 2009). African Americans who report experiencing racial discrimination have greater psychological distress (Brown et al., 2000; Murry, Brown, Brody, Cutrona, \& Simons, 2001), lower self-esteem (Utsey, Ponterotto, Reynolds, \& Cancelli, 2000), and greater symptoms of depression (Banks, Kohn-Wood, \& Spencer, 2006; Watkins, Hudson, Howard-Caldwell, Siefert, \& Jackson, 2011). Although there is ample evidence demonstrating the debilitating effects of racial discrimination on individual mental health (Pascoe \& Smart Richman, 2009; Broudy et al., 2007), less is known about its effects in the context of intimate partnership. Understanding these effects is important due to the interdependence of couples and the reciprocal associations of stress and mental health among those in close relationships (Benazon \& Coyne, 2000; Bodenmann, 1997; Meyler, Stimpson, \& Peek, 2007). With an increased risk of couple dissolution in the context of lowered mental health (Butterworth \& Rodgers,

*Department of Family and Child Sciences, Florida State University, Tallahassee, FL.

${ }^{\dagger}$ Department of Psychology, University of Georgia, Athens, GA.

Correspondence concerning this article should be addressed to Sharde' McNeil, Department of Family and Child Sciences, Florida State University, 225 Sandels Building, Tallahassee, FL 32306.

E-mail: sm11aj@my.fsu.edu 
2008), it is essential to understand what may put partners at this risk, and conversely, what may function as buffering agents for this particular stressor. Thus, the purpose of this study was to examine the relationship between partners' perceived racial discrimination and depressive symptoms, and the potential moderating role of spousal social support, in a sample of heterosexual African American couples.

\section{Guiding Framework}

Social stress theory is a guiding framework for understanding the effects of racial discrimination on mental health outcomes (Aneshensel, Rutter, \& Lachenbruch, 1991; Pearlin, 1989). This theory posits that stress resulting from one's social position in society leads to fewer resources to cope with these circumstances, and subsequently causes an increase in mental health problems (Aneshensel et al., 1991; Pearlin, 1989). This study therefore examined perceived racial discrimination as a source of stress stemming from a disadvantaged social position and spousal support as a resource that might buffer the impact of discrimination in the context of intimate partnership.

According to Schwartz and Meyer (2010), the social stress framework consists of both within- and between-group examinations of the stress-mental health link. Specifically, this theory was used to examine interindividual variation in experiences of racial discrimination and mental health outcomes among a sample of African American heterosexual couples (Schwartz \& Meyer, 2010). Examining within-group variability in the discrimination process highlights the assumption that social groups are heterogeneous in their exposure to stress and their coping mechanisms. Accordingly, social stress theory provides a rubric for examining within-group variation in a sample of African Americans.

\section{Discrimination Experienced by African Americans and Mental Health Outcomes}

Racial discrimination is a chronic and debilitating stressor that has been shown to have negative impacts on the mental health of African Americans (Clark, Anderson, Clark, \& Williams, 1999). In a large-scale national study, approximately half (49\%) of African American adults reported experiencing discrimination, with close to $90 \%$ of them stating it was due to their race/ethnicity (Kessler, Mickelson, \& Williams, 1999). Furthermore, in a review of 66 studies, Pieterse, Todd, Neville, and Carter (2012) found a significant positive association $(r=.20)$ between perceived discrimination and mental health outcomes among African American adults. Thus, racial discrimination, and its influence on mental health outcomes, is important to consider when examining the stress process within African Americans.

To date, most studies on the association between racial discrimination and mental health outcomes have focused on actor effects, that is, the relationship between one's own experiences with racial discrimination and one's own psychological well-being (see Paradies, 2006, for a review). Although this is important, it is not the only process that needs to be considered in order to understand the effects of discrimination on mental health in the context of intimate partner relationships. Specifically, stressors do not occur in isolation and disturbances in one area can bring about disturbances in other areas and possibly with other people in close relationships. According to Pearlin (1989), "...the stressors experienced by one individual often become problems for others who share the same role sets" (p. 247). Thus, partners experiencing discrimination may use their relationships directly or indirectly as a sounding board and create secondary stress for others (St. Jean \& Feagin, 1998). Discrimination impacts individuals differently (Ong et al., 2009) and the unique nature of this process can be explored through examining not only actor (within person) effects but also partner (across person) effects in the stress-outcome link. 
Spousal Support as a Moderator

Differential effects of racial discrimination on mental health outcomes may reflect differences in the amount of support available. When faced with stressful stimuli, proximal adaptive or maladaptive coping resources are typically sought (Pearlin, 1989). Various positive coping strategies, including those of support systems, have been shown to moderate the effects of perceived discrimination and mental health (Ajrouch, Reisine, Lim, Sohn, \& Ismail, 2010; Noh \& Kaspar, 2003; Thompson, 2006) such that the relationship between discrimination and mental health problems was buffered by the presence of adequate support systems. According to Brondolo, ver Halen, Pencille, Beatty, and Contrada (2009), "a supportive social network promotes a sense of security and connectedness, helping the individual to understand that discrimination is a shared experience" (p. 75). Although discrimination is suggested as a shared experience, little empirical evidence exists on the stress-coping impact in the context of intimate partner relationships.

Studies that have examined the influence of support on the association between discrimination and lowered mental health have focused on the general effects of social support (e.g., Ajrouch et al., 2010); however, the unique impact of spousal support in couple relationships (Coyne \& DeLongis, 1986) has not been identified. Spousal support for the purposes of this study was defined as how often a partner feels they can be intimate, confide, and share their worries and fears with their mate. With the intimate nature of close relationships, one's partner may be a valuable resource for coping with the negative effects of racial discrimination when discriminatory events arise (Cowdery et al., 2009; St. Jean \& Feagin, 1998). For instance, in a qualitative study of 15 heterosexual African American couples, a central theme was "Pulling Together," which described how couples valued family solidarity as evidenced by their discourses on working together to protect the family from the effects of ethnic discrimination (Cowdery et al., 2009). Spousal support may be qualitatively different from other sources of support (Coyne \& DeLongis, 1986); therefore, examining its influence as a distinct concept may offer a unique perspective for understanding variability in the stress process among African American couples.

\section{The Present Study}

Most studies on racial discrimination and mental health have focused on intra-individual effects or the relationship between one's perceived racial discrimination and their own mental health outcomes (i.e., actor effects). In contrast, little is known about interpersonal effects or the relationship between one's perceived racial discrimination and mental health outcomes for the partner in close relationships (i.e., partner effects). This study addresses this gap by examining the actor and partner effects of perceived racial discrimination and depressive symptomology in a sample of African American couples. Furthermore, the buffering effects of spousal social support were also assessed. Three hypotheses that were explored were as follows:

(1) On the basis of prior findings, we hypothesized that there would be positive actor effects of perceived discrimination and depressive symptoms for both women and men.

(2) We posited that there would be positive partner effects of perceived discrimination and depressive symptoms for both women and men.

(3) We hypothesized that spousal support would buffer these relationships such that the strength of the relationships between perceived discrimination and depressive symptoms would decrease for those with high levels of spousal support. 


\section{METHOD}

\section{Sample and Procedure}

A sample of 487 African American engaged or married couples from both rural and urban areas of the southeastern United States were recruited for the Program of Strong African American Marriages, a preventive intervention designed to enhance relationship quality among African American couples. Couples were eligible for the study if they were at least 21 years of age, either already married or engaged to be married within 1 year of recruitment, and willing to pray and have others pray for them as a couple. All participants completed questionnaires before completing the program and the data reported here are from the preintervention assessment.

\section{Measures}

\section{Perceived racial discrimination}

Couples completed the Perceived Racism/Discrimination scale (PRD; Murry, Brown, Brody, Cutrona, \& Simons, 2001). The PRD is a 13-item measure designed to assess the level of perceived discrimination in African Americans. Respondents were asked independently to rate how often they experienced racism or discrimination on a 4-point Likert scale $(1=$ never, 2 once or twice, $3=$ a few times, $4=$ several times). Sample items included "How often has someone said something derogatory or insulting to you or your partner just because you are African American or are a part of an African American family?" Scores for the measures were created by summing across the 13 items; higher scores indicate higher levels of perceived discrimination. Cronbach's alpha was .89 and .92 for women and men, respectively.

\section{Spousal support}

Spousal social support was measured using the Spousal Specific Support Scales (Culp \& Beach, 1998). Couples completed the 14-item assessment, based on the Interpersonal Support Evaluation List that assesses their agreement with statements such as "I feel intimate with my mate" and "my mate is someone I can confide in." Each item was measured on a 5 -point Likert scale $(1=$ almost never; 2 = rarely; $3=$ occasionally; $4=$ often; 5 = almost always). The Internal Support Evaluation List has been shown to have good internal consistency, with as ranging from .77 to .90, in addition to good discriminant validity (Cohen, Mermelstein, Kamarck, \& Hoberman, 1985). For this study, items were summed into a composite variable with higher scores indicating higher levels of spousal social support ( $\alpha=.76$ and .67 for women and men, respectively).

\section{Depressive symptoms}

Male and female depressive symptomatology was measured by the Beck Depression Inventory II (BDI-II; Beck, Steer, \& Brown, 1996). Couples completed the 21-item assessment and indicated what best described them in the past week on a 4-point scale (e.g., Sadness- $0=I$ do not feel sad; 1 = I feel sad; 2 = I am sad all the time and I can't snap out of it; 3 = I am so sad or unhappy that I can't stand it). The severity of women's and men's depressive symptomatology was constructed by summing the response of their respective measure. The internal reliability was high for both women (.89) and men (.81).

\section{RESULTS}

\section{Analytic Strategy}

Due to the nonindependence of the data, we utilized the actor-partner interdependence model (Kenny \& Ledermann, 2010) to test the hypotheses. The model was computed using 
Mplus software (Muthén \& Muthén, 2010). Men- and women-reported perceived discrimination was correlated as well as the residual terms corresponding to women and men's depressive symptoms. Actor effects were present when an individual's perceived discrimination was associated with a change in his or her depressive symptoms, and partner effects were present when an individual's perceived discrimination was associated with a change in their partner's depressive symptoms.

To test for moderation, all independent variables were mean-centered to reduce collinearity and for ease of interpretation. Interactions were created with the centered independent variables (women and men's perceived discrimination) and the moderators (women and men spousal social support). Significant interactions indicated the presence of moderation and the results were graphed to depict the slopes at one standard deviation above and below the mean.

\section{Preliminary Analyses}

Descriptive statistics and correlations between study variables are presented in Table 1. Couples in this study were married an average of 9.75 years $(S D=9.26)$ and earned on average $\$ 40,000-\$ 50,000$ a year in household income. The more household income a couple earned, the greater experiences of racial discrimination both men and women tended to report. The longer the couple was married, the more experiences of discrimination women and men reported and the less depressive symptoms men tended to report. Women reported significantly lower levels of perceived discrimination, $t(486)=-3.52, \quad p<.001$ and significantly more depressive symptoms than men, $t(486)=4.82, p<.001$. In addition, men reported receiving significantly higher levels of spousal support than women, $t(486)=-3.68, p<.001$. Women's and men's perceived discrimination were positively associated with their depressive symptomology. On average, men and women reported high levels of spousal support that were negatively associated with depressive symptomology of men and women. There were no significant relationships between reports of men and women's perceived discrimination and their partner's depressive symptomology.

\section{Main Effects Model}

To test our first two hypotheses, we examined a model with the actor and partner effects of perceived discrimination of women and men on depressive symptomology, controlling for household income and years married (see Figure 1). There were positive and significant actor effects for women's $(\beta=.13, S E=.06, p<.05)$ and men's $(\beta=.15$, $S E=.05, p<.01)$ perceived discrimination and their depressive symptomology when controlling for partner effects, household income, and years married. No partner effects were present in the model.

\section{Moderation Analysis}

To test the moderation analysis, spousal support and two interaction terms were entered into the model shown in Figure 1: (1) women's perceived discrimination and women's perceived spousal support and (2) men's perceived discrimination and men's perceived spousal support. Results of the full model are shown in Table 2. The interaction between men's perceived discrimination and men's spousal support was significantly associated with men's depressive symptoms. This interaction was further examined by graphing spousal support at one standard deviation above the mean and one standard deviation below the mean (see Figure 2). The results showed that higher levels of perceived discrimination were associated with more depressive symptoms for 


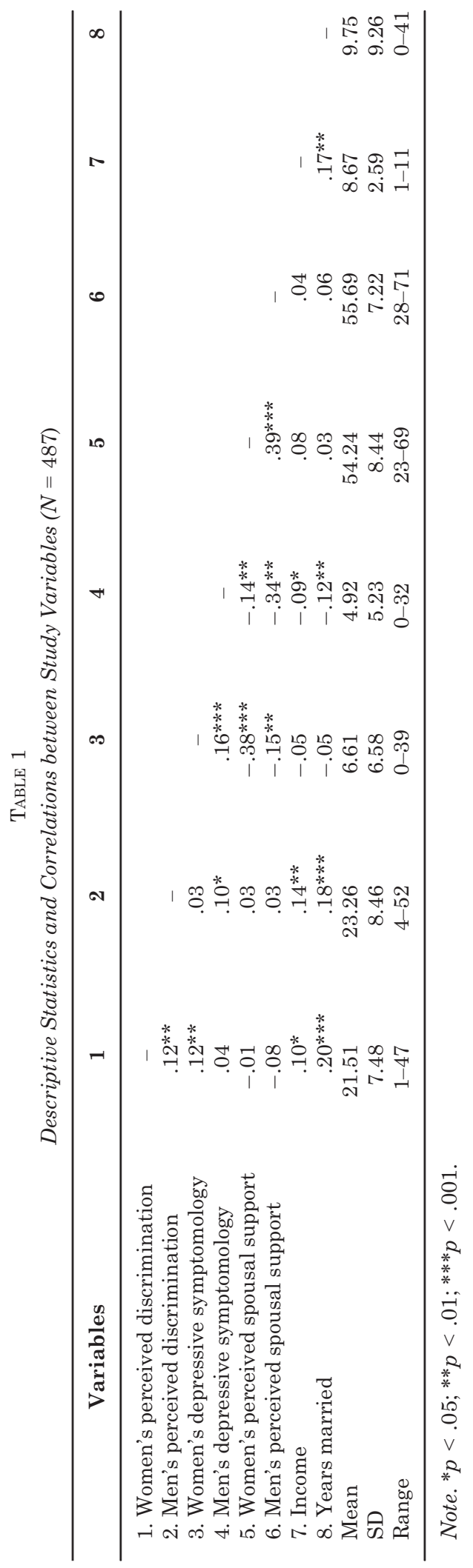




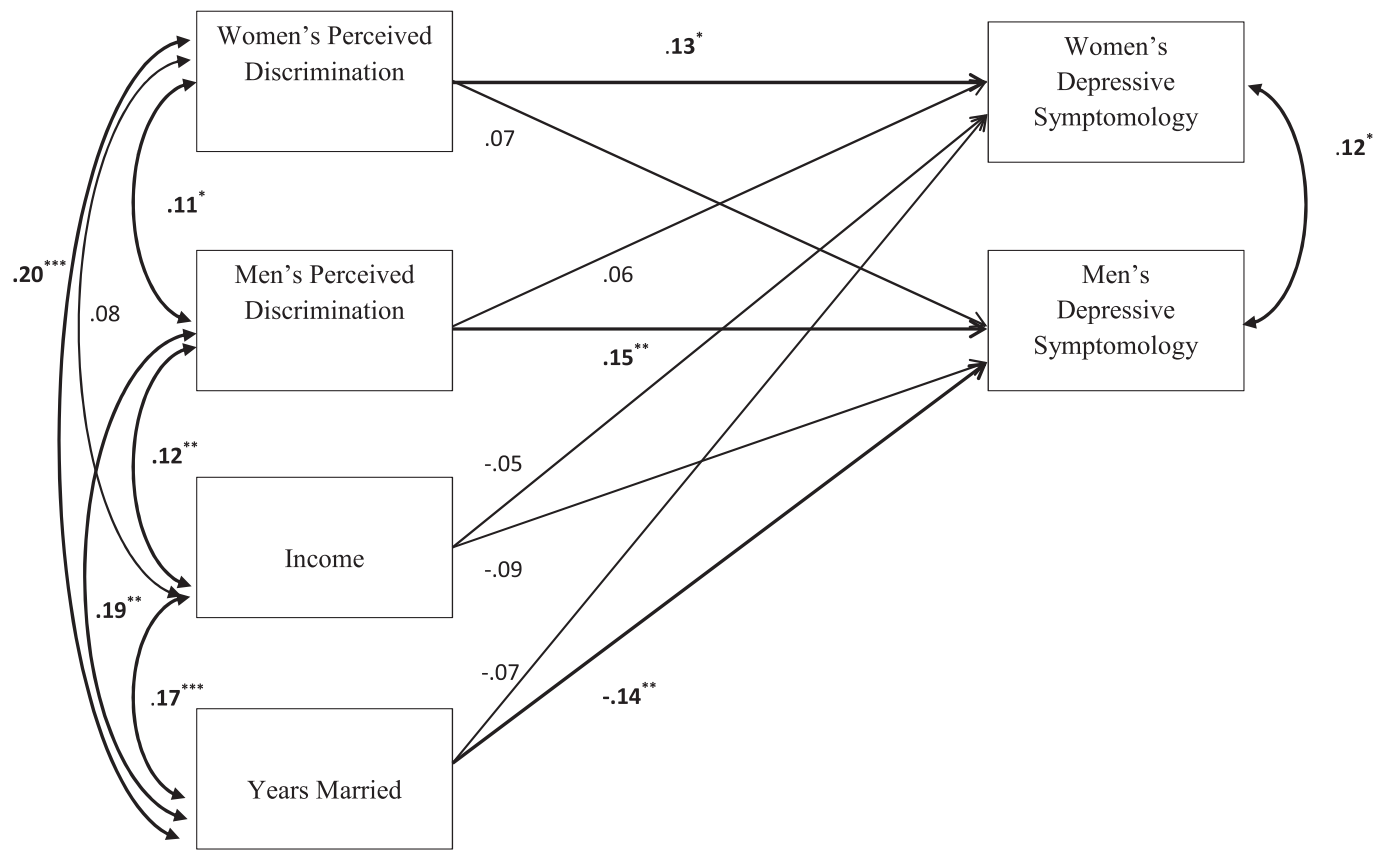

Figure 1. Analytic Model for the Association between Women and Men's Perceived Discrimination and Depressive Symptomology, Controlling for Couple Income. Residual Terms for Wife and Husband Depressive Symptomology were Correlated. Model Presents Standardized Betas. ${ }^{*} p<.05, * * p<.01, * * * p<.001$

Results of Perceived Spousal Support as a Moderator of Women and Men's Perceived Discrimination and Depressive Symptomology ( $n=487$ dyads)

\begin{tabular}{lccc}
\hline & $\boldsymbol{b}$ & $\boldsymbol{S E}$ & $\boldsymbol{t}$ \\
\hline Actor effects & & & \\
Women PRD $\rightarrow$ Women DEP & .11 & .05 & $2.41^{*}$ \\
Men PRD $\rightarrow$ Men DEP & .10 & .03 & $3.31^{* *}$ \\
Women SS $\rightarrow$ Women DEP & -.30 & .04 & $-7.70^{* * *}$ \\
Men SS Men DEP & -.27 & .03 & $-8.91^{* * *}$ \\
Partner effects & & .03 & .78 \\
$\quad$ Women PRD $\rightarrow$ Men DEP & .02 & .04 & 1.22 \\
Men PRD $\rightarrow$ Women DEP & .04 & .01 & -1.14 \\
Interaction effects & & .00 & $-2.45^{*}$ \\
$\quad$ Women PRD $\times$ Women SS $\rightarrow$ Wife DEP & -.01 & -.01 & \\
Men PRD $\times$ Men SS $\rightarrow$ Men DEP &
\end{tabular}

Note. $\mathrm{PRD}=$ perceived racial discrimination; $\mathrm{DEP}=$ depressive symptoms; $\mathrm{SS}=$ spousal support. Predictor variables are centered. Model included household income and years married as covariates.

${ }^{*} p<.05 ; * * p<.01, * * * p<.001$.

men with low support $(B=.17, S E=.02, p<.001)$; however, the discriminationdepressive symptom link was not significant for men with high levels of spousal support $(B=.03, S E=.03, p>.05)$. In other words, spousal support was shown to have a buffering effect for the effects of racial discrimination on depression for men in this sample. 


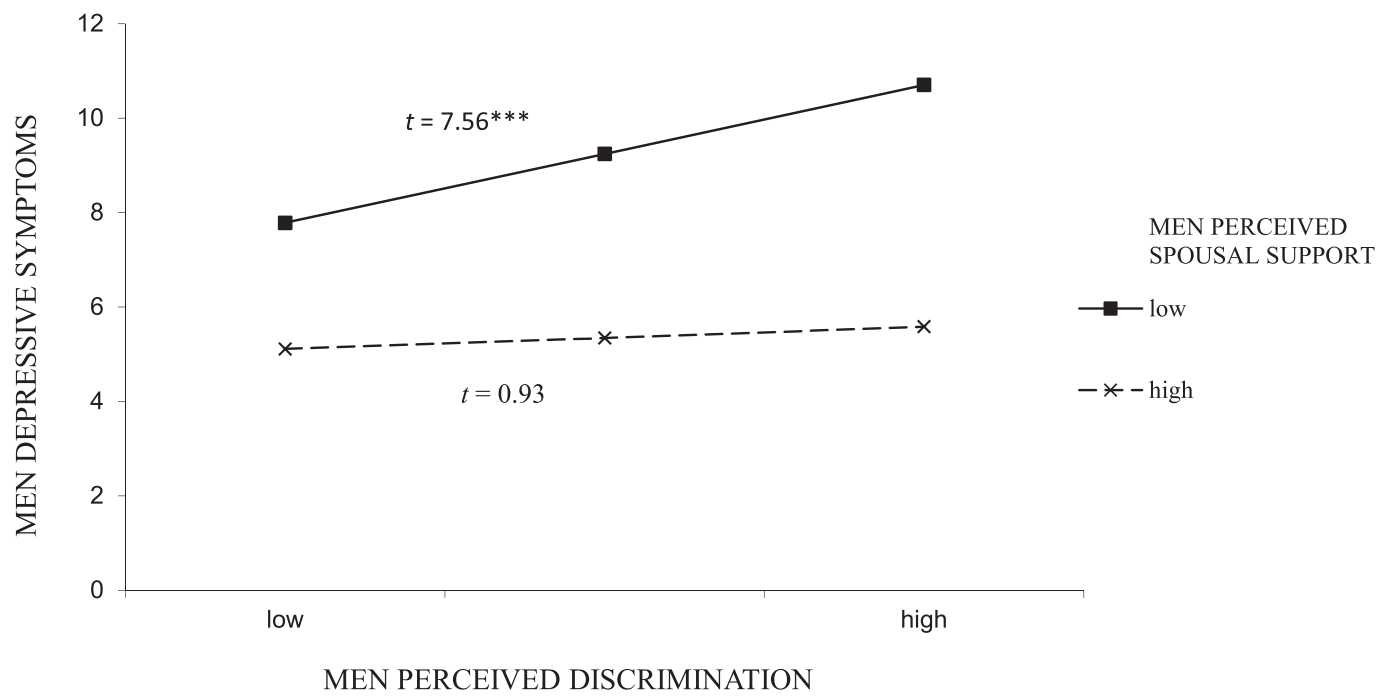

Figure 2. Men Perceived Spousal Support as a Moderator of Men Perceived Discrimination and Men Depressive Symptoms. ${ }^{* *} p<.001$

\section{DISCUSSION}

This study utilized the actor-partner interdependence model to explore the effects of perceived racial discrimination on depressive symptoms, controlling for the effects of household income and length of marriage, in a sample of African American heterosexual couples. We found that women's and men's perceived racial discrimination was significantly associated with them having greater depressive symptoms. However, when examined in the context of spousal support, we found that spousal support moderated the actor effect for men such that experiences of racial discrimination were associated with increased levels of depressive symptoms for men with low levels of spousal support and not for men with high levels of spousal support. No partner effects were found in this study.

The first hypothesis regarding the presence of actor effects was supported. As expected, experiences with perceived discrimination did predict more depressive symptoms for both men and women. These results are consistent with previous research demonstrating a significant positive link between racial discrimination and own depressive symptoms (Banks et al., 2006; Watkins, Hudson, Howard-Caldwell, Siefert, \& Jackson, 2011). This finding suggests that discrimination as a social stressor has negative intrapersonal effects on mental health among African American couples.

Despite reporting more experiences with discrimination, the association between men's perceived racial discrimination and depressive symptoms was more complex. At first glance, it appears that stress resulting from discrimination affects men's mental health; however, results from the moderation analysis suggested otherwise. These analyses showed that at low levels, but not high levels of spousal support, racial discrimination was related to depressive symptoms for men. In other words, the relationship between discrimination and depressive symptomology existed only for those with less than adequate levels of spousal support.

Spousal support did not moderate this relationship for women. This nonsignificant finding has important implications given that levels of depressive symptoms remain salient with higher levels of perceived discrimination despite the amount of spousal support available. This may indicate that other support systems are instrumental for buffering 
these effects or that the impact of discrimination on mental health is pervasive for these women. The former possibility is particularly relevant given the nature of the present sample as women may have obtained support from faith group activities or informally from others who belonged to their faith group.

Gender differences in the stress response may help explain some of these findings. According to Taylor et al. (2000), women are more likely to provide emotional support during stressful circumstances. As such, women may be more likely to provide support to their partners who experience racial discrimination and feel the need to protect them from such social injustices (Cowdery et al., 2009). Furthermore, women are more likely than men to display and report internalizing symptoms (Banks et al., 2006), whereas men's responses may present themselves in outward expressions or externalizing symptoms (e.g., Goff, Di Leone, \& Kahn, 2012; Riina \& McHale, 2010). When female partners do not provide this support, men may internalize their stress either in place of or in conjunction with externalizing symptoms.

Interestingly, no partner effects were significant suggesting that experiences of men and women's discrimination do not influence their partner's depressive symptomology. This is contrary to our hypothesis as the impact of couples' stress processes on one another's well-being has been found in some studies (e.g., Benazon \& Coyne, 2000; Bodenmann, 1997; Meyler et al., 2007). This is not to say that there are no partner effects of discrimination, but that other causal mechanisms and buffering effects not examined here may better explain this process.

It is worth noting that we found that couples who were married longer and had higher incomes had greater perceived discrimination. A possibility for these findings is that years married may serve as a proxy of age of participants, based on the assumption that older participants were married longer. As such, older participants may have had a greater historical experience with discrimination than younger participants. Also, research has shown that African Americans with higher incomes report more experiences with discrimination (e.g., Dailey, Kasl, Holford, Lewis, \& Jones, 2010). It has been suggested that those individuals may be in communities and careers with more interactions with Whites (Sigelman \& Welch, 1991) and face prejudice due to being a minority within a majority culture (Pickett \& Wilkinson, 2008). Furthermore, there is evidence that discrimination has attenuating effects on the inverse association between socioeconomic position and depression, suggesting that higher income has conditional buffering effects on mental health outcomes (Hudson et al., 2012). Further studies are needed to dissect these findings.

This study must be considered in light of several limitations. First, this study relied on cross-sectional data and therefore, causal inferences cannot be made. It is possible that depressive symptoms lead to a hypervigilance regarding unfair treatment. There is also a possibility that discrimination experiences sensitized participants to later experiences of discrimination. Longitudinal research assessing each of these constructs at different time points is needed to examine the predictive nature of perceived racial discrimination on mental health.

In addition, our investigation focused on a main effects model to assess the relationship between a sociocultural stressor and mental health. Additional research is needed to understand the different pathways by which perceived discrimination impacts depressive symptomology in the couple context. Due to variation in the stress process, there may be multiple pathways and these should be explored.

It should also be noted that the results obtained from our sample may not generalize to other African American couples because our participants were recruited in the southeast and had to be willing to pray to be included in the study. Finally, we focused on the effects of spousal support as a protective factor for discrimination and depressive symptomology but other forms of support may be instrumental in buffering this association. Future 
research should examine the protective effects of religious and general social support within the African American couple context.

Despite these limitations, our findings are consistent with the variability in the stress process presented in social stress theory and support the need to examine the interdependence of the stress process among those in close relationships. Studies examining the effects of discrimination on mental health may need to consider these effects among those with varying levels of support. Although spousal support appears to have little influence on the discrimination-depressive symptomology link for African American women, this study revealed that it is influential for African American men. One explanation for this pattern of results derives from the observation that women tend to be more concerned than men with maintaining good relationships with their family and friends (Gilligan, 1993). As a consequence, wives are likely better at providing support than are husbands, raising the question of whether increasing husbands' ability to provide support more effectively in marital interventions might not decrease wives' depression. Further research is needed to continue to dissect these processes and to understand the mechanisms and moderators through which racial discrimination is related to mental health.

\section{REFERENCES}

Ajrouch, K. J., Reisine, S., Lim, S., Sohn, W., \& Ismail, A. (2010). Perceived everyday discrimination and psychological distress: Does social support matter? Ethnicity and Health, 15, 417-434. doi:10.1080/13557858.2010. 484050.

Aneshensel, C., Rutter, C. M., \& Lachenbruch, P. S. (1991). Social structure, stress and mental health, competing conceptual and analytic models. American Sociological Review, 56, 166-178. doi:10.2307/2095777.

Banks, K. H., Kohn-Wood, L. P., \& Spencer, M. (2006). An examination of the African American experience of everyday discrimination and symptoms of psychological distress. Community Mental Health Journal, 42, 555570. doi:10.1007/s10597-006-9052-9.

Beck, A. T., Steer, R. A., \& Brown, O. K. (1996). Beck Depression Inventory Manual (2nd ed.). San Antonio, TX: Psychological Corporation.

Benazon, N. R., \& Coyne, J. C. (2000). Living with a depressed spouse. Journal of Family Psychology, 14, 71-79. doi:10.1037/0893-3200.14.1.71.

Bodenmann, G. (1997). Dyadic coping - A systemic-transactional view of stress and coping among couples: Theory and empirical findings. European Review of Applied Psychology, 47, 137-140.

Brondolo, E., ver Halen, N. B., Pencille, M., Beatty, D., \& Contrada, R. J. (2009). Coping with racism: A selective review of the literature and a theoretical and methodological critique. Journal of Behavioral Medicine, 32, 64-88. doi:10.1007/s10865-008-9193-0.

Broudy, R., Brondolo, E., Coakley, V., Brady, N., Cassells, A., Tobin, J. N. et al. (2007). Perceived ethnic discrimination in relation to daily moods and negative social interactions. Journal of Behavioral Medicine, 30, 31-43. doi:10.1007/s10865-006-9081-4.

Brown, T. N., Williams, D. R., Jackson, J. S., Neighbors, H. W., Torres, M., Sellers, S. L., \& Brown, K. T. (2000). "Being black and feeling blue": The mental health consequences of racial discrimination. Race and Society, 2 , 117-131. doi: 10.101016/S1090-9524(00)00010-3

Butterworth, P., \& Rodgers, B. (2008). Mental health problems and marital disruption: Is it the combination of husbands' and wives' mental health problems that predicts later divorce? Social Psychiatry and Psychiatric Epidemiology, 43, 758-763. doi: 10.1007/s00127-008-0366-5.

Clark, R., Anderson, N. B., Clark, V. R., \& Williams, D. R. (1999). Racism as a stressor for African Americans: A biopsychosocial model. American Psychologist, 54, 805-816. doi:10.1037/0003-066X.54.10.805.

Cohen, S., Mermelstein, R., Kamarck, T., \& Hoberman, H. M. (1985). Measuring the functional components of social support. In I. G. Sarason \& B. R. Sarason (Eds.), Social support: Theory, research, and applications. The Hague, the Netherlands: Martinus Niijhoff.

Cowdery, R. S., Scarborough, N., Knudson-Martin, C., Seshadri, G., Lewis, M. E., \& Mahoney, A. R. (2009). Gendered power in cultural contexts: Part II. Middle class African American heterosexual couples with young children. Family Process, 48, 25-39. doi:10.1111/j.1545-5300.2009.01265.x.

Coyne, J. C., \& DeLongis, A. (1986). Going beyond social support: The role of social relationships in adaptation. Journal of Consulting and Clinical Psychology, 54, 454-460. doi:10.1037/0022-006X.54.4.454. 
Culp, L. N., \& Beach, S. R. H. (1998). Marriage and depressive symptoms: The role and bases of self-esteem differ by gender. Psychology of Women Quarterly, 22, 647-663.

Dailey, A. B., Kasl, S. V., Holford, T. R., Lewis, T. T., \& Jones, B. A. (2010). Neighborhood- and individual-level socioeconomic variation in perceptions of racial discrimination. Ethnicity and Health, 15, 145-163. doi:10.1080/ 13557851003592561.

Gilligan, C. (1993). In a different voice: Psychological theory and women's development. Cambridge, MA: Harvard University Press.

Goff, P. A., Di Leone, B. A., \& Kahn, K. B. (2012). Racism leads to pushups: How racial discrimination threatens subordinate men's masculinity. Journal of Experimental Social Psychology, 48, 1111-1116.

Hudson, D. L., Bullard, K. M., Neighbors, H. W., Geronimus, A. T., Yang, J., \& Jackson, J. S. (2012). Are benefits conferred with greater socioeconomic position undermined by racial discrimination among African American men? Journal of Men's Health, 9, 127-136. doi:10.1016/j.jomh.2012.03.006.

Kenny, D. A., \& Ledermann, T. (2010). Detecting, measuring, and testing dyadic patterns in the actor-partner interdependence model. Journal of Family Psychology, 24, 359-366. doi:10.1016/j.jesp.2012.03.015.

Kessler, R. C., Mickelson, K. D., \& Williams, D. R. (1999). The prevalence, distribution, and mental health correlates of perceived discrimination in the United States. Journal of Health and Social Behavior, 40, 208-230. doi:10.2307/2676349.

Lincoln, K. D., \& Chae, D. H. (2010). Stress, marital satisfaction, and psychological distress among African Americans. Journal of Family Issues, 31, 1081-1105. doi:10.1177/0192513X10365826.

Meyler, D., Stimpson, J. P., \& Peek, M. K. (2007). Health concordance within couples: A systematic review. Social Science and Medicine, 64, 2297-2310. doi:10.1016/j.socscimed.2007.02.007.

Murry, V. M., Brown, P. A., Brody, G. H., Cutrona, C. E., \& Simons, R. L. (2001). Racial discrimination as a moderator of the links among stress, maternal psychological functioning, and family relationships. Journal of Marriage and Family, 63, 915-926. doi: 10.1111/j.1741-3737.2001.00915.x

Muthén, L. K., \& Muthén, B. (2010). Mplus user's guide. Los Angeles, CA: Muthén \& Muthén.

Noh, S., \& Kaspar, V. (2003). Perceived discrimination and depression: Moderating effects of coping, acculturation, and ethnic support. American Journal of Public Health, 93, 232-238. doi:10.2105/AJPH.93.2.232.

Ong, A. D., Fuller-Rowell, T., \& Burrow, A. L. (2009). Racial discrimination and the stress process. Journal of Personality and Social Psychology, 96, 1259-1271. doi:10.1037/a0015335.

Paradies, Y. (2006). A systematic review of empirical research on self-reported racism and health. International Journal of Epidemiological, 35, 888-901. doi:10.1093/ije/dyl056.

Pascoe, E. A., \& Smart Richman, L. (2009). Perceived discrimination and health: A meta-analytic review. Psychological Bulletin, 135, 531-554.

Pearlin, L. I. (1989). The sociological study of stress. Journal of Health and Social Behavior, 30, 241-256. doi:10.2307/2136956.

Pickett, K., \& Wilkinson, R. (2008). People like us: Ethnic group density effects on health. Ethnicity and Health, 13, 321-334.doi: 10.1080/13557850701882928

Pieterse, A. L., Todd, N. R., Neville, H. A., \& Carter, R. T. (2012). Perceived racism and mental health among Black American adults: A meta-analytic review. Journal of Counseling Psychology, 59, 1-9. doi:10.1037/ a0026208.

Riina, E. M., \& McHale, S. M. (2010). Parents' experiences of discrimination and family relationship qualities: The role of gender. Family Relations, 59, 283-296.doi: 10.1111/j.1741-3729.2010.00602.x

Schwartz, S., \& Meyer, I. H. (2010). Mental health disparities research: The impact of within and between group analyses on tests of social stress hypotheses. Social Science and Medicine, 70, 1111-1118. doi: 10.1016/j.socsci med.2009.11.032

Sigelman, L., \& Welch, S. (1991). Black Americans' views of racial inequality: The dream deferred. Cambridge, MA: Harvard University Press.

St. Jean, Y. \& Feagin, J. R. (1998). The family costs of White racism: The case of African American families. Journal of Comparative Family Studies, 29, 297-312.

Taylor, S. E., Klein, L. C., Lewis, B. P., Gruenewald, T. L., Gurung, A. R. R., \& Updegraff, J. A. (2000). Biobehavioral responses to stress in females: Tend-and-befriend, not fight-or-flight. Psychological Review, 107, 411-429. doi:10.1037/0033-295X.107.3.411.

Thompson, V. L. S. (2006). Coping responses and the experience of discrimination. Journal of Applied Social Psychology, 36, 1198-1214. doi:10.1111/j.0021-9029.2006.00038.x.

Utsey, S. O., Ponterotto, J. G., Reynolds, A. L., \& Cancelli, A. A. (2000). Racial discrimination, coping, life satisfaction, and self-esteem among African Americans. Journal of Counseling and Development, 78, 72-80. doi:10.1002/j.1556-6676.2000.tb02562.x.

Watkins, D. C., Hudson, D. L., Caldwell, C. H., Seifert, K., \& Jackson, J. S. (2011). Discrimination, mastery, and depressive symptoms among African American men. Research on Social Work Practice, 21, 269-277.doi: 10. 1177/1049731510385470.

Fam. Proc., Vol. x, xxxx, 2013 